\title{
Chronic cough in patients with sleep-disordered breathing
}

\author{
K.K.Y. Chan*\#, A.J. Ing*, L. Laks*, G. Cossa*, P. Rogers* and S.S. Birring"
}

ABSTRACT: Chronic cough can be the sole presenting symptom for patients with obstructive sleep apnoea. We investigated the prevalence, severity and factors associated with chronic cough in patients with sleep-disordered breathing (SDB).

We invited 108 consecutive patients who had been referred for evaluation of SDB to complete a comprehensive questionnaire on respiratory and sleep health, which included the Leicester Cough Questionnaire (cough specific quality of life; LCQ), Epworth Sleepiness Scale (ESS) and the Mayo Clinic gastro-oesophageal questionnaire. Chronic cough was defined as cough for a duration of $>\mathbf{2}$ months.

$33 \%$ of patients with SDB reported a chronic cough. Patients with a chronic cough had impaired cough related-quality of life affecting all health domains (mean \pm SEM LCQ score 17.7 \pm 0.7 ; normal=21). Patients with SDB and chronic cough were predominantly females $(61 \%$ versus $17 \%$; $p<0.001)$ and reported more nocturnal heartburn $(28 \%$ versus $5 \% ; p=0.03)$ and rhinitis $(44 \%$ versus $14 \% ; p=0.02$ ) compared to those without SDB. There were no significant differences in ESS, respiratory disturbance index, body mass index, or symptoms of breathlessness, wheeze, snoring, dry mouth and choking between those with cough and those without.

Chronic cough is prevalent in patients with SDB and is associated with female sex, symptoms of nocturnal heartburn and rhinitis. Further studies are required to investigate the impact of continuous positive airway pressure therapy on cough associated with SDB to explore the mechanism of this association.

KEYWORDS: Chronic cough, Leicester Cough Questionnaire, respiratory disturbance index, sleep-disordered breathing, visual analogue scale

hronic cough is a common condition referred to respiratory physicians. The most common causes of chronic cough in nonsmokers are asthma, gastro-oesophageal reflux (GOR) and rhinitis (also known as upper airway cough syndrome) [1]. Despite thorough investigations, the aetiology of cough is unexplained in up to $20 \%$ of patients [2]. Unexplained chronic cough has been reported in patients who snore and who have sleep-disordered breathing (SDB) [3]. Chronic cough can be the sole manifestation of obstructive sleep apnoea (OSA) and can be effectively treated by continuous positive airway pressure (CPAP) therapy [3]. Furthermore, cough symptoms have been associated with day time somnolence in general population studies [4]. The mechanism of the association between cough and SDB are not known. GOR, rhinitis and upper airway inflammation have been proposed [3]. The aim of this study was to investigate the prevalence, severity and factors associated with chronic cough in patients with SDB.

\section{METHODS}

\section{Subjects}

Consecutive patients with symptoms of SDB referred to a sleep disorders clinic were recruited between August and December 2007. All subjects underwent overnight polysomnography (PSG) and were invited to participate in the study. Patients were excluded if they were smokers, had known respiratory disease, were taking angiotensin converting enzyme (ACE) inhibitors, had a recent upper respiratory tract infection in the previous 4 weeks or had a respiratory disturbance index (RDI) of $<5$ events $\cdot h^{-1}$ on PSG. All patients gave informed consent to participate and the protocol was approved by the Concord Repatriation General Hospital Ethics Committee in the Sydney South West Area Health Service (Sydney, Australia).

\section{Questionnaires}

All patients completed a structured questionnaire recording demographic details, presence of cough symptoms, cough severity and conditions
AFFILIATIONS

*Respiratory Investigations Unit, Dept of Thoracic Medicine, Concord Repatriation General Hospital, Sydney, and

\# Dept of Respiratory Medicine, Campbelltown and Camden Hospitals, Campbelltown, Australia. -Dept of Respiratory Medicine, King's College Hospital, London, UK.

CORRESPONDENCE

S.S. Birring

Dept of Respiratory Medicine

King's College Hospital

London

SE5 9RS

UK

E-mail: surinder.birring@kch.nhs.uk

Received:

July 142009

Accepted after revision:

Oct 192009 
commonly associated with cough. Chronic cough was defined as cough duration $>2$ months in response to the following question to be consistent with the definition of chronic cough: "if you have cough, how long have you had it?" The following questionnaires or tests were administered.

1) Patient demographics: general medical history, presence of rhinitis or hayfever, dry mouth, choking, snoring, smoking history, medications and alcohol consumption.

2) Cough symptom severity: cough visual analogue scale (VAS; 0-100 mm) [5].

3) Cough related health status: the Leicester Cough Questionnaire (LCQ) [6]. The LCQ measures quality of life related to chronic cough in three domains: physical, psychological and social. Each domain is scored between 1 and 7, the latter indicating no impairment in quality of life. The total score ranges from 3 to 21 .

4) Sleepiness: Epworth Sleepiness Scale (ESS). A score of $\geqslant 9$ indicates significant sleepiness, range 0-21 [7].

5) Respiratory symptoms and smoking status: patients completed an adapted version of the International Union Against Tuberculosis and Lung Disease questionnaire [8, 9]. Breathlessness: "do you ever have trouble breathing?"; sputum: "do you usually bring up any phlegm from your chest during the day, or at night, in the winter?"; and wheeze: "have you had wheezing or whistling in your chest in the last 12 months?"

6) GOR symptoms: the Mayo Clinic GOR questionnaire. This is a validated questionnaire that records the symptoms of heartburn, nocturnal heartburn, regurgitation and dysphagia [10-14].

\section{PSG}

Each subject underwent a standard overnight PSG sleep study (Compumedics, Victoria, Australia) that included central and occipital electroencephalograms, electrooculogram and submental electromyogram (EMG) to determine sleep stage. The electrocardiogram and diaphragm and tibialis anterior EMGs were monitored. Thoracoabdominal excursions were measured using respiratory inductance plethysmography, nasal flow by a nasal cannula-pressure transducer system, nasal and oral airflow by a thermistor and snoring with a room microphone. Arterial blood oxyhaemoglobin saturation was recorded with a pulse oximeter. Sleep staging was scored in 30-s epochs. Respiratory events and arousals were defined and scored according to the recommendations of the American Sleep Disorders Association Taskforce [15]. Patients with SDB were defined as having an RDI of $\geqslant 5$ events $\cdot \mathrm{h}^{-1}$.

\section{Statistical analysis}

Patient demographics were described as mean \pm SEM or mean \pm SD. The Chi-squared and Fisher Exact tests were used to compare the characteristics of patients with SDB and chronic cough and those without chronic cough. Pearson correlation coefficients were used to examine the correlation between RDI, quality of life and cough symptoms. A p-value of $<0.05$ was considered statistically significant.

\section{TABLE 1 Subject characteristics}

$\begin{array}{lc}\text { Subjects } & 55 \\ \text { Male } & 37(67) \\ \text { Female } & 18(33) \\ \text { Mean age yrs } & 53 \pm 13 \\ \text { Mean BMI kg } \mathbf{m}^{-2} & 31 \pm 8 \\ \text { Epworth Sleepiness Scale } & 9 \pm 5 \\ \text { Cough duration }>\mathbf{2} \text { months } & 18(33) \\ \text { RDI events } \cdot \mathbf{h}^{-1} & \\ \text { RDI } 5-15 & 14(26) \\ \text { RDI }>15, \leqslant 30 & 12(22) \\ \text { RDI }>30 & 29(53)\end{array}$

Data are presented as $n, n(\%)$ or mean \pm SD. BMI: body mass index RDI: respiratory disturbance index

\section{RESULTS}

108 patients were assessed for participation in this study and 53 patients were excluded: seven $(7 \%)$ patients were current smokers; $17(16 \%)$ reported chronic obstructive pulmonary disease or asthma; eight $(7 \%)$ patients reported recent upper respiratory tract infection; 21 (19\%) patients reported current use of ACE inhibitors; and seven (7\%) patients had an RDI $<5$ events $\cdot h^{-1}$ on PSG. Three out of seven patients without SDB reported cough, two were taking ACE inhibitors and one had a history of respiratory disease. The remaining four patients without SDB did not report cough.

The remaining 55 patients were recruited for this study (table 1). All patients were life-long nonsmokers and did not report significant occupational exposure. Five (9\%) patients were taking proton pump inhibitors, $\mathrm{H} 2$ antagonist medication or both. $18(33 \%)$ patients had chronic cough. Patients with SDB and chronic cough had impaired quality of life affecting all health domains (table 2). There was no relationship between RDI and prevalence or severity of cough (VAS: $r=-0.05, p=0.84$; quality of life-related to cough, LCQ total score: $\mathrm{r}=-0.11, \mathrm{p}=0.67)$.

Patients with SDB and chronic cough compared with those without cough were more likely to be females ( $61 \%$ versus $19 \%$; $\mathrm{p}=0.002)$ and report symptoms of nocturnal heartburn $(28 \%$ versus $5 \% ; p=0.02)$, rhinitis $(44 \%$ versus $14 \% ; p=0.01)$, dysphagia ( $33 \%$ versus $11 \% ; \mathrm{p}=0.04)$ and chest pain $(44 \%$ versus $19 \% ; \mathrm{p}=0.05)$. Of the patients with chronic cough and $\mathrm{SDB}, 22 \%$ did not report symptoms of GOR disease or rhinitis.

\begin{tabular}{lcc} 
TABLE 2 & $\begin{array}{l}\text { Leicester Cough Questionnaire scores for } \\
\text { chronic cough subjects with sleep-disordered } \\
\text { breathing }\end{array}$ \\
Domain & Score & SEM \\
\hline Physical & 5.8 & 0.2 \\
Psychological & 5.8 & 0.3 \\
Social & 6.1 & 0.3 \\
Total & 17.7 & 0.7 \\
\hline
\end{tabular}




\begin{tabular}{|c|c|c|c|c|}
\hline \multirow[t]{2}{*}{ TABLE 3} & \multicolumn{4}{|c|}{$\begin{array}{l}\text { Comparison of patients with sleep-disordered } \\
\text { breathing and chronic cough versus those } \\
\text { without cough }\end{array}$} \\
\hline & & Chronic cough & No cough & p-value \\
\hline Female & & $11(61)$ & 7 (19) & 0.002 \\
\hline Male & & $7(39)$ & $30(81)$ & 0.002 \\
\hline \multicolumn{5}{|c|}{ Respiratory symptoms } \\
\hline Dyspnoea & & $10(56)$ & $15(41)$ & 0.39 \\
\hline Sputum pro & duction & $2(11)$ & $0(0)$ & 0.10 \\
\hline Wheezing & & $4(22)$ & $8(22)$ & 1.0 \\
\hline \multicolumn{5}{|c|}{ OSA syndrome } \\
\hline ESS score & & 10 & 8 & 0.27 \\
\hline Snoring & & $15(83)$ & $32(86)$ & 1 \\
\hline \multicolumn{5}{|c|}{$\begin{array}{l}\text { GOR disease-related } \\
\text { symptoms }\end{array}$} \\
\hline Nocturnal h & eartburn & $5(28)$ & $2(5)$ & 0.02 \\
\hline Heartburn & & $8(44)$ & $9(24)$ & 0.21 \\
\hline Acid regurg & tation & $6(33)$ & $12(32)$ & 1 \\
\hline Dysphagia & & $6(33)$ & $4(11)$ & 0.04 \\
\hline Chest pain & & $8(44)$ & 7 (19) & 0.046 \\
\hline Thyroid dise & & $2(11)$ & $1(3)$ & 0.25 \\
\hline Rhinitis & & $8(44)$ & $5(14)$ & 0.01 \\
\hline Hypertensior & & $5(28)$ & $10(27)$ & 0.9 \\
\hline Cardiovascu & ar disease $^{\#}$ & $6(33)$ & $12(32)$ & 0.9 \\
\hline
\end{tabular}

There was increased prevalence of thyroid disease in patients with cough compared to those without, but it did not reach statistical significance $(11 \%$ versus $3 \% ; p=0.25)$ (table 3$)$. There were no significant differences in symptoms of dyspnoea, wheeze, sputum production, snoring, dry mouth and choking between the patients with chronic cough compared to those without. There were no significant differences in ESS, snoring and RDI between the two groups (table 3). Cardiovascular disease (hypertension, ischaemic heart disease and heart failure) did not differ significantly between groups (table 3). No patients had central sleep apnoea.

\section{DISCUSSION}

This is the first study to investigate the prevalence and severity of chronic cough in patients with SDB. Our study demonstrates that chronic cough is an important and common symptom associated with SDB. Of the subjects with SDB, 33\% had chronic cough. Patients with SDB and chronic cough had significantly impaired quality of life due to cough that affected all health domains. Patients with chronic cough were more likely to be female and have symptoms of nocturnal heartburn and rhinitis.

GOR is common in patients with OSA $[16,17]$. The negative intrathoracic pressure associated with inspiratory efforts against an upper airway resistance in OSA may lead to regurgitation of gastric contents. The reduced upper and lower oesophageal sphincter tone during sleep may also potentiate
GOR [18]. ING et al. [19] have reported a high prevalence of GOR in patients with SDB, where GOR events were temporally related to apnoea or hypopnoea events. The severity of GOR has been associated with the severity of respiratory disturbance due to SDB [20]. Furthermore, GOR disease has been identified as an independent risk factor associated with snoring, sleep disturbance and day time somnolence [17]. Nasal CPAP therapy has been reported to reduce the number of GOR events and oesophageal acidity in patients with OSA [21]. These findings suggest that GOR disease may play an important role in SDB and possibly SDB-associated cough, since GOR disease is one of the most commonly reported causes of chronic cough [1]. Only $44 \%$ of our patients with chronic cough and SDB reported heartburn and $28 \%$ had nocturnal heartburn, suggesting that not all SDB-related cough is GOR disease mediated.

A number of observations suggest that cough may be mediated by airway inflammation associated with SDB. We found that subjects with SDB and chronic cough were more likely to report symptoms of rhinitis than those without cough. Rhinitis, also known as upper airway cough syndrome, is a common cause of chronic cough, often seen in combination with other conditions causing cough [1]. Upper airway secretions are thought to directly activate cough receptors in a hypersensitive hypopharynx and larynx or indirectly through increased nasal resistance and inflammation [22-24]. We were unable to establish whether particular aetiologies of rhinitis were more prevalent in SDB cough; this should be addressed in the future. The sensitivity of the cough reflex is worth investigating in future studies since it may reveal important insights into the relationship between cough and SDB. Lower airway inflammation is also important. We have previously reported an increase in airway neutrophils in patients with OSA-associated cough and speculated that it may be caused by episodes of snoring or apnoeas $[3,25]$. The frequency of apnoeas was not related to the severity of cough. This may seem surprising at first but probably reflects a nonlinear relationship as seen with other aggravants of cough [26]. It is possible that cough may be due to snoring alone in a susceptible individual, since cough has been linked to snoring in the absence of SDB [27, 28]. Finally, cough may be associated with the presence of obesity rather than SDB. However, a recent study did not find an association between body mass index and cough frequency [29]; this suggests that the presence of SDB is likely to be important in the pathogenesis of cough.

SDB is frequently associated with comorbidities, particularly cardiovascular disease. Chronic cough is an uncommon but well recognised presentation of left ventricular dysfunction. Airway and pulmonary cough receptors are thought to be activated by extra vascular fluid overload. There was no significant difference in the prevalence of cardiovascular disease between patients with cough than those without. Further characterisation of patients with echocardiography would be necessary to exclude left ventricular dysfunction as an important mechanism with confidence. Thyroid disease is another common comorbidity seen in SDB and has recently been associated with chronic cough. It has been hypothesised that homing of autoimmune inflammatory cells from the thyroid gland to the airways may cause cough. We found a higher prevalence of thyroid disease in SDB associated with 
cough than that without cough. This was not statistically significant but our study was not powered or designed to detect differences in the prevalence of thyroid disease. Further characterisation of patients that includes measurement of autoantibodies and thyroid function tests is necessary to establish the importance of thyroid disease in patients with SDB cough.

We found that patients with chronic cough and SDB were more likely to be female. Female patients outnumber males in most cough clinics. Female sex is associated with a higher cough frequency and severity and a more heightened cough reflex compared with males [30,31]. Our findings suggest that the initial assessment of patients with SDB should enquire about the presence of cough, particularly in female patients.

A limitation of this study is the lack of a control group. This ideally should be subjects without SDB, matched for age, sex and body mass index. Cough was not reported by patients with normal polysomnography in the absence of known tussive stimuli but this group comprised of just four patients. Further studies, preferably case-control in design are needed to confirm our findings. A number of studies have investigated the prevalence of chronic cough in the general population. The prevalence of chronic cough varies due to differences in study methodologies and factors such as age, smoking, air pollution and viral infections. Di PEDE et al. [32] reported a 3\% prevalence of chronic cough in nonsmoking Mexican-Americans and 8\% in the Anglo-Saxons in Arizona, USA. VIEGI et al. [33] reported a prevalence of $9 \%$ in Northern Italy and PEAT et al. [34] reported a prevalence of $10.7 \%$ in Busselton, Australia. More recently, VOLL-AANERUD et al. [35] reported an incidence of chronic cough of $9.2 \%$ in females and $7.7 \%$ in males in Bergen, Norway. The prevalence of chronic cough in patients with SDB seen in our study was much higher than that reported in general population studies. The use of subjective questionnaires rather than objective tests may have led to an inaccurate estimation of the presence and severity of cough, GOR disease and rhinitis. The LCQ, International Union Against Tuberculosis and Lung Disease and Mayo Clinic GOR questionnaires have been well validated and used widely [6, $7,9,36-39]$. The purpose of this study was to identify risk factors associated with chronic cough in patients with SDB; establishing the aetiology of cough was beyond the scope of this study. Further studies of SDB cough should investigate patients using standardised diagnostic protocols for chronic cough incorporating objective tools such as cough monitoring and 24-h oesophageal $\mathrm{pH}$ studies. Establishing a temporal association between episodes of apnoea, GOR and cough will be important to demonstrate causality between cough and SDB. A further limitation is that the large number of patients excluded from this study may have affected the prevalence of cough. The most likely possibility is that that the prevalence of chronic cough was underestimated since most excluded subjects were exposed to well-known tussive stimuli.

In conclusion, chronic cough is prevalent in patients with SDB and impacts on their quality of life. SDB cough is not well recognised by physicians and it is possible that some patients referred to specialist clinics for investigation of cough are misdiagnosed. It is important to recognise SDB cough because preliminary reports suggest it responds well to specific therapy for SDB. A follow-up study to investigate the response to CPAP therapy is warranted, preferably as a controlled trial.

\section{STATEMENT OF INTEREST}

None declared.

\section{ACKNOWLEDGEMENTS}

We would like to thank R. Collins, B. Lee and L. Seccombe (Concord Repatriation General Hospital, Sydney, Australia) for their assistance with organising and reporting polysomnography studies.

\section{REFERENCES}

1 Irwin RS, Baumann MH, Bolser DC, et al. Diagnosis and management of cough executive summary: ACCP evidence-based clinical practice guidelines. Chest 2006; 129: Suppl. 1, 1S-23S.

2 Birring SS, Brightling CE, Symon FA, et al. Idiopathic chronic cough: association with organ specific autoimmune disease and bronchoalveolar lymphocytosis. Thorax 2003; 58: 1066-1070.

3 Birring SS, Ing AJ, Chank K, et al. Obstructive sleep apnoea: a cause of chronic cough. Cough 2007; 3: 7.

4 Klink ME, Dodge R, Quan SF. The relation of sleep complaints to respiratory symptoms in a general population. Chest 1994; 105: 151-154.

5 Oey IF, Bal S, Spyt TJ, et al. The increase in body mass index observed after lung volume reduction may act as surrogate marker of improved health status. Respir Med 2004; 98: 247-253.

6 Birring SS, Prudon B, Carr AJ, et al. Development of a symptom specific health status measure for patients with chronic cough: Leicester Cough Questionnaire (LCQ). Thorax 2003; 58: 339-343.

7 Johns MW. Reliability and factor analysis of the Epworth Sleepiness Scale. Sleep 1992; 15: 376-381.

8 Birring SS, Morgan AJ, Prudon B, et al. Respiratory symptoms in patients with treated hypothyroidism and inflammatory bowel disease. Thorax 2003; 58: 533-536.

9 Burney PG, Laitinen LA, Perdrizet S, et al. Validity and repeatability of the IUATLD (1984) Bronchial Symptoms Questionnaire: an international comparison. Eur Respir J 1989; 2: 940-945.

10 Avidan B, Sonnenburg A, Schnell TG, et al. There are no reliable symptoms for erosive oesophagitis and Barrett's oesophagus: endoscopic diagnosis is still essential. Aliment Pharmacol 2002; 16: 735-742.

11 Nandurkar S, Locke GR 3rd, Murray JA, et al. Rates of endoscopy and endoscopic findings among people with frequent symptoms of gastroesophageal reflux in the community. Am J Gastroenterol 2005; 100: 1459-1465.

12 Chiocca JC, Olmos JA, Salis GB, et al. Prevalence, clinical spectrum and atypical symptoms of gastro-oesophageal reflux in Argentina: a nationwide population-based study. Aliment Pharmacol Ther 2005; 22: 331-342.

13 Mokhlesi B, Morris AL, Huang CF, et al. Increased prevalence of gastroesophageal reflux symptoms in patients with COPD. Chest 2001; 119: 1043-1048.

14 Rascon-Aguilar IE, Pamer M, Wludyka P, et al. Role of gastroesophageal reflux symptoms in exacerbations of COPD. Chest 2006; 130: 1096-1101.

15 Carskadon MA, Rechtschaffen A, Monitoring and staging human sleep. In: Kryger M, Roth T, Dement W, eds. Principles and Practice of Sleep Medicine. 4th Edn. Elsevier, 2008; pp. 1359-1377.

16 Demeter P, Pap A. The relationship between gastroesophageal reflux disease and obstructive sleep apnea. J Gastroenterol 2004; 39: $815-820$

17 Janson C, De Baker W, Gislason T, et al. Prevalence of sleep disturbances among young adults in three European countries. Sleep 1995; 18: 589-597. 
18 Pasricha PJ. Effect of sleep on gastroesophageal physiology and airway protective mechanisms. Am J Med 2003; 115: Suppl. 3A, 114S-118S.

19 Ing $\mathrm{AJ}, \mathrm{Ngu} \mathrm{MC}$, Breslin $\mathrm{AB}$. Obstructive sleep apnea and gastroesophageal reflux. Am J Med 2000; 108: Suppl. 4a, 120S-125S.

20 Demeter P, Visy KV, Magyar P. Correlation between severity of endoscopic findings and apnea-hypopnea index in patients with gastroesophageal reflux disease and obstructive sleep apnea. World J Gastroenterol 2005; 11: 839-841.

21 Kerr PMD, Shoenut JP, Steens RD, et al. Nasal continuous positive airway pressure: a new treatment for nocturnal gastroesophageal reflux? J Clin Gastroenterol 1993; 17: 276-280.

22 Irwin RS, Pratter MR, Holland PS, et al. Postnasal drip causes cough and is associated with reversible upper airway obstruction. Chest 1984; 85: 346-352.

23 Rappai M, Collop N, Kemp S, et al. The nose and sleep-disordered breathing: what we know and what we do not know. Chest 2003; 124: 2309-2323.

24 Lofaso F, Coste A, d'Ortho MO, et al. Nasal obstruction as a risk factor for sleep apnoea syndrome. Eur Respir J 2000; 16: 639-643.

25 Birring SS, Parker D, Brightling CE, et al. Induced sputum inflammatory mediator concentrations in chronic cough. Am J Respir Crit Care Med 2004; 169: 15-19.

26 Patterson RN, Johnston BT, MacMahon J, et al. Oesophageal pH monitoring is of limited value in the diagnosis of "reflux-cough". Eur Respir J 2004; 24: 724-727.

27 Corbo GM, Fuciarelli F, Foresi A, et al. Snoring in children: association with respiratory symptoms and passive smoking. BMJ 1989; 299: 1491-1494.

28 Larsson LG, Lundbäck B, Jönsson E, et al. Are symptoms of obstructive sleep apnoea syndrome related to bronchitic symptoms or lung function impairment? Report from the obstructive lung disease in Northern Sweden study. Respir Med 1998; 92: 283-288.
29 Birring SS, Yousaf, NY, Matos S, et al. Normal range for 24-hour cough frequency. Thorax 2008; 63: Suppl. 7, P65.

30 French CT, Fletcher KE, Irwin RS. Gender differences in healthrelated quality of life in patients complaining of chronic cough. Chest 2004; 125: 482-488.

31 French CT, Fletcher KE, Irwin RS. A comparison of gender differences in health-related quality of life in acute and chronic coughers. Chest 2005; 127: 1991-1998.

32 Di Pede C, Viegi G, Quackenboss JJ, et al. Respiratory symptoms and risk factors in an Arizona population sample of Anglo and Mexican-American whites. Chest 1991; 99: 916-922.

33 Viegi G, Paoletti P, Prediletto R, et al. Prevalence of respiratory symptoms in an unpolluted area of northern Italy. Eur Respir J 1988; 1: 311-318.

34 Peat JK, Haby M, Spijker J, et al. Prevalence of asthma in adults in Busselton, Western Australia. BMJ 1992; 305: 1326-1329.

35 Voll-Aanerud M, Eagan TM, Wentzel-Larsen T, et al. Changes in respiratory symptoms and health-related quality of life. Chest 2007; 131: 1890-1897.

36 Burney PG, Chinn S, Britton JR, et al. What symptoms predict the bronchial response to histamine? Evaluation in a community survey of the bronchial symptoms questionnaire (1984) of the International Union Against Tuberculosis and Lung Disease. Int $J$ Epidemiol 1989; 18: 165-173.

37 Torén K, Brisman J, Jarvholm B. Asthma and asthma-like symptoms in adults assessed by questionnaires. A literature review. Chest 1993; 104: 600-608.

38 Locke GR, Talley NJ, Weaver AL, et al. A new questionnaire for gastroesophageal reflux disease. Mayo Clinic Proc 1994; 69: 539-547.

39 Brightling CE, Ward R, Wardlaw AJ, et al. Airway inflammation, airway responsiveness and cough before and after inhaled budesonide in patients with eosinophilic bronchitis. Eur Respir J 2000; 15: 682-686. 